\title{
Mifepristone as pre-induction cervical ripening agent in term pregnancy
}

Sir,

We hereby report the results of a prospective randomized study where we compared efficacy of mifepristone and prostaglandin (PGE2) gel for pre-induction cervical ripening.

This study includes all primigravida who fulfilled the inclusion criteria and planned for induction of labour after obtaining informed written consent. Inclusion criteria included were primigravida with singleton pregnancy in cephalic presentation with maternal age 18-35 years, with gestational age after 37 weeks (by dating scan) with intact membranes, reactive FHR pattern in live fetus and Bishop's score <6. Exclusion criteria included were clinically estimated fetal weight $<2,000$ and $>4,000 \mathrm{~g}$, antepartum hemorrhages, chorioamnionitis, medical complication and previous myomectomy. The allocation to mifepristone group or PGE2 gel group was done using computer generated random number. On the scheduled day of induction initial Bishop's score was assessed in both groups at 8 am. One group was administered mifepristone $200 \mathrm{mg}$ orally once and another group was administered intra-cervical PGE2 gel at 6 hours interval for maximum of three doses. Subsequent Bishop's score was assessed at 6 hours, 12 hours, 18 hours and 24 hours in the both the groups. After 24 hours tablet misoprostol $25 \mu \mathrm{gm}$ was administered vaginally every 4 hours (maximum 6 doses $150 \mu \mathrm{gm}$ ) or till the women enters in to active labor, whichever was earlier. When the women entered into active labor, ARM was done and if required oxytocin drip was started for augmentation of labor, but not earlier than $4 \mathrm{hrs}$ after the last dose of misoprostol. Progress of labour, uterine contractions and the fetal heart rate were monitored using partogram. If fetal heart rate pattern was normal with satisfactory progress of labor, those women were kept for vaginal delivery or else, if progress was unsatisfactory or variable fetal heart pattern, those women underwent caesarean section. The outcome in the mother and baby were noted. The parameters studied were mean Bishop's score (0 hour, 6 hours, 12 hours, 18 hours and 24 hours), requirement of tablet Misoprostol, requirement of augmentation, mode of delivery, induction delivery interval, APGAR score at 1 minute and 5 minutes and NICU admission $>24$ hours. Improvement of Bishop's score was significantly higher in PGE2 gel group at 6 hours, 12 hours, 18 hours as compared to mifepristone group. Augmentation with oxytocin rate was higher in PGE2 gel group $73(73 \%)$ when compared to mifepristone group $69(71.1 \%)$. Induction delivery interval was significantly shorter in PGE2 gel group with a 'p' value $<0.001$. Vaginal delivery rate was higher in mifepristone group $63(63 \%)$ as compared to PGE2 gel group $48(48 \%)$. The most common indication for caesarean section was fetal distress in both the groups. There was no significant difference noted for neonatal outcomes in terms of apgar score and NICU stay $>24$ hours in both the groups.

Although, studies have shown mifepristone is better cervical ripening agent than PGE2 gel, our study failed to do so. ${ }^{1-3}$ This may be due to inclusion of both primi and multigravida in those studies whereas our study includes only primigravida.

Nikita Sharma, Seetesh Ghose*, Setu Rathod

Department of Obstetrics and Gynecology, Mahatma Gandhi Medical College and Research Institute, Pondicherry, India

*Correspondence:

Seetesh Ghose, E-mail: seetesh@mgmcri.ac.in.

\section{REFERENCES}

1. Gaikwad V, Mittal B, Puri M. Comparative analysis of safety, efficacy and fetomaternal outcome of induction of labour with mifepristone versus intracervical dinoprostone gel. Res J Pharm Biol Chem Sci. 2014;5(2):611-6.

2. Sah G. Mifepristone versus intracervical prostaglandin E2 gel for cervical ripening in primigravid patients at term. Int $\mathbf{J}$ Reprod Contracept Obs Gynecol. 2018;7(3):824-8.

3. Arumugaselvi B, Sujathasenthil S, Anandan $\mathrm{H}$. Comparative study of oral mifepristone and endocervical prostaglandins E2 gel as preinduction cervical ripening agent in parturition. Int J Sci Study. 2017; 129:129.

Cite this article as: Sharma N, Ghose S, Rathod S. Mifepristone as pre-induction cervical ripening agent in term pregnancy. Int J Reprod Contracept Obstet Gynecol 2019;8:2574. 